\title{
Presença de parvovírus B19 em Manaus, AM
}

\author{
Occurrence of parvovirus B19 in Manaus, AM
}

\author{
Regina Maria Pinto de Figueiredo ${ }^{1,2}$, Mário Lira de Lima1, \\ Tânia Maria Carvalho Almeida1 e Michele de Souza Bastos ${ }^{1,2}$
}

\begin{abstract}
RESUM0
A investigação de 1.107 casos de doenças exantemáticas em Manaus permitiu a identificação dos primeiros 47 casos de parvovírus humano B19 na cidade. O parvovírus B19 foi caracterizado por uma combinação de sinais e sintomas como febre, cefaléia, artralgia, mialgia e exantema. A freqüência de exantema foi maior em indivíduos menores de quinze anos e, no adulto, prevaleceram a febre e artropatias. 0 maior número de casos foi registrado em 1999. Quanto à faixa etária, nos menores de 15 anos, predominou o sexo masculino e, entre os adultos, o feminino. Este estudo, portanto, ressalta a necessidade de se elucidar a causa de doenças exantemáticas que ocorrem no Estado do Amazonas e indica que estudos são necessários, no que concerne à atividade viral.
\end{abstract}

Palavras-chaves: Doença exantemática. Eritema infeccioso. Infecção.

\begin{abstract}
Investigation of 1,107 cases of exanthematous diseases in Manaus allowed the identification of the first 47 cases of human parvovirus B19 in the city. Parvovirus B19 was characterized by a combination of signs and symptoms such as fever, chronic headache, arthralgia, myalgia and exanthema. The frequency of exanthema was higher in individuals less than fifteen years old. In adults, fever and arthropathy were the most frequent symptoms. The highest number of cases was registered in 1999. Regarding gender, male sex was predominant among infected individuals younger than fifteen years old, and female sex in adults. This study, therefore, underscores the necessity for clarifying the causes of exanthematous illnesses that occur in the State of Amazonas and investigation of the viral activity.
\end{abstract}

Key-words: Exanthematous diseases. Infectious erythema. Infection.

0 parvovírus humano B19, descrito por Cossart cols ${ }^{6}$ em 1975, pertence à família Parvoviridae, é um patógeno humano comum, associado a inúmeras doenças. Geralmente é responsável por infecções na infância que causam eritema infeccioso ( EI) ${ }^{3}$. Em alguns casos, pode estar associado a doenças severas, tais como: artropatias agudas ou persistentes, crises aplásticas transitórias (TAC), hodropsia fetal e perda fetal ${ }^{4}$, que podem ocorrer em infecções durante 0 segundo trimestre de gravidez ${ }^{5}$, miocardites ${ }^{11}$ e ou hepatite.

0 parvovírus B19 humano já foi detectado em várias regiões do mundo, mostrando sua ampla ocorrência e distribuição universal ${ }^{1}$. No entanto, estudos sobre infecções causadas por este agente ainda são escassos no Brasil.

As primeiras descrições do parvovírus no país datam de 1989, no Estado do Rio de Janeiro ${ }^{7}$, em doadores de sangue sadios e, em Belém ${ }^{13}$, em estudo realizado com crianças em fase aguda de doença exantemática.

Sabe-se que vários agentes virais como rubéola, sarampo, parvovírus B19 e arboviroses (oropouche, mayaro e dengue) são responsáveis pela ocorrência de doenças exantemáticas eartropatias. Sendo assim, se fez necessário o diagnóstico diferencial das doenças exantemáticas, o que proporcionou a descrição dos primeiros casos de parvovírus B19 na Cidade de Manaus, Amazonas.

1. Fundação de Medicina Tropical do Amazonas, Manaus, AM. 2. Universidade Estadual do Amazonas, Manaus, AM.

Endereço para correspondência: Dra. Regina Maria Pinto de Figueiredo. Gerência de Virologia/FMTAM. Av. Pedro Teixeira 25, Dom Pedro, 69040-000 Manaus, AM, Brasil,

Telefax: 5592 3238-3762

Celular: 5592 9126-1758

e-mail: regina68@ig.com.br

Recebido para publicação em 20/4/2004

Aceito em 18/6/2005 


\section{MATERIAL E MÉTODOS}

No período de janeiro de 1999 a dezembro de 2003, foi realizado um estudo para investigação das doenças exantemáticas no Serviço de Arbovirologia da Fundação de Medicina Tropical do Amazonas (FMTAM). Foram incluídos na pesquisa todos os pacientes com suspeita clínica de doença exantemática, independente de idade ou sexo, residentes em Manaus.

As amostras sanguíneas foram coletadas por venopunção em tubos estéreis, sem anticoagulante. Os soros foram obtidos por centrifugação, transferidos para tubos estéreis e estocados a $-20^{\circ} \mathrm{C}$ até a realização dos testes laboratoriais.

Inicialmente as amostras foram testadas utilizando-se 0 teste sorológico MAC-ELISA ( Enzyme-linked-immunoabsorvente assay) para detectar a presença de anticorpos IgM para arbovírus (dengue, mayaro e oropouche), de acordo com a técnica descrita por Kuno e cols ${ }^{12}$. Diante de um resultado negativo, estas amostras foram então testadas pelos kits ELISA comerciais Rubenostika IgM (Organon Teknika) para rubéola; pelo Enzygnost antimeasles IgM ( Hoechst-Behring) para sarampo; e também pelo EIA (MACEIA) usando anticorpos de captura IgM para parvovírus B19 humano, como descrito previamente 8 .

\section{RESULTAD0S}

Foram testadas 1.107 amostras de pacientes com suspeita clínica de doenças exantemáticas. Destas, 278 (25,1\%) foram testadas para parvovírus B19 humano, onde 47 (17\%) foram identificadas com anti-IgM positivo para parvovírus, o que resultou na descrição dos primeiros casos de parvovírus B19 no Estado do Amazonas.
Na distribuição anual dos casos de parvovírus, o maior percentual de diagnosticados foi em 1999 com 68,8\%, seguido por 2000 com 13,6\% em 2002 com 9,5\%. Sendo que, em 2003 foi diagnosticado apenas um caso (Figura 1).

Amaioria dos casos de parvovírus B19 ocorreu em menores de 15 anos (70\%), com predomínio do sexo masculino (81\%). Contudo, na faixa etária adulta, foi observado que o maior número de casos ocorreu em mulheres (Tabela 1).

Ainfecção por parvovírus B19 é caracterizada por um variado grupo de sintomas. A freqüência $(93,9 \%)$ de exantema foi substancialmente alta em menores de 15 anos de idade, enquanto os sintomas como febre, mialgia e artralgia prevaleceram nos adultos (Tabela 2).

Tabela 1 - Distribuição dos casos com sorologia positiva para parvovírus, por sexo e faixa etária. Manaus, 1999 a 2003.

\begin{tabular}{lcrcrcr}
\hline Faixa etária & Feminino & \multicolumn{1}{c}{$\%$} & Masculino & $\%$ & Total & $\%$ \\
\hline$<15$ & 12 & 57,0 & 21 & 81,0 & 33 & 70,2 \\
15 a 19 & 2 & 9,5 & 1 & 3,8 & 3 & 6,4 \\
20 a 29 & 2 & 9,5 & 3 & 11,4 & 5 & 10,6 \\
30 a 39 & 3 & 14,0 & 1 & 3,8 & 4 & 8,5 \\
40 a 49 & 1 & 5,0 & - & - & 1 & 2,0 \\
50 a 59 & 1 & 5,0 & - & - & 1 & 2,0 \\
$>59$ & - & - & - & - & - & - \\
\hline Total & $\mathbf{2 1}$ & $\mathbf{1 0 0 , 0}$ & $\mathbf{2 6}$ & $\mathbf{1 0 0 , 0}$ & $\mathbf{4 7}$ & $\mathbf{9 9 , 7}$ \\
\hline
\end{tabular}

Tabela 2 - Distribuição dos sinais e sintomas mais comuns observados nos casos de parvovírus humano diagnosticados na FMTAM, por grupo de idade. Manaus, 1999 a 2003.

\begin{tabular}{|c|c|c|c|c|c|c|}
\hline \multirow[t]{2}{*}{ Sintomas Clínicos } & \multicolumn{2}{|c|}{$<15$ anos $\left(n^{0}=33\right)$} & \multicolumn{2}{|c|}{$\geq 15$ anos $\left(n^{0}=14\right)$} & \multicolumn{2}{|c|}{ Total $\left(n^{0}=47\right)$} \\
\hline & $n^{0}$ & $\%$ & $\mathrm{n}^{0}$ & $\%$ & $\mathrm{n}^{0}$ & $\%$ \\
\hline Febre & 13 & 39,4 & 11 & 78,5 & 24 & 51,1 \\
\hline Cefaléia & 7 & 21,2 & 9 & 64,3 & 16 & 34,0 \\
\hline Mialgia & 2 & 6,1 & 10 & 71,4 & 12 & 25,5 \\
\hline Artralgia & 3 & 9,1 & 11 & 78,5 & 14 & 30,0 \\
\hline Exantema & 31 & 93,9 & 10 & 71,4 & 41 & 87,2 \\
\hline
\end{tabular}

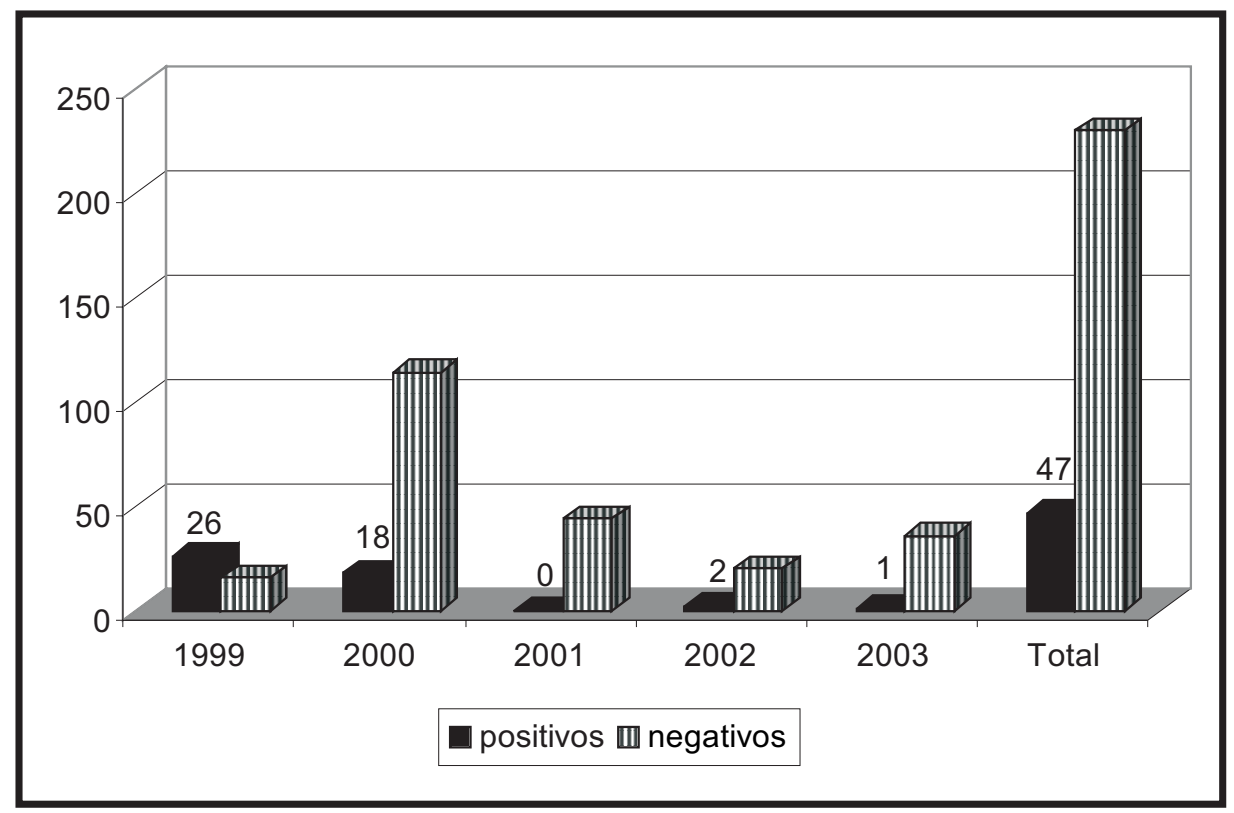

Figura 1 - Distribuição dos casos de parvovírus B19 diagnosticados na FMTAM, segundo o ano. Manaus, 1999 a 2003. 


\section{DISCUSSÃ0}

Durante décadas, a etiologia de doenças designadas como rubella-like permaneceu sem confirmação do diagnóstico. Apesar de investigações de rotina para outras infecções exantemáticas, é possível que o parvovírus B19 seja 0 agente de alguns dos casos sem diagnóstico? .

Em Manaus, a positividade para o parvovírus B19 foi confirmada regularmente ao longo do período estudado. 0 maior número de casos ocorreu em 1999, ressaltando que estavam incluídas amostras coletadas em 1998, seguindo-se com menor freqüência em 2000 e sem registros pelo laboratório de casos positivos em 2001, e apenas dois casos em 2002. Esta doença não apresentou sazonalidade, podendo se manifestar em epidemias ou casos isolados, de acordo com a literatura ${ }^{2}$.

Quanto à faixa etária e ao sexo, o maior número de casos ocorreu em crianças do sexo masculino, de 0-14 anos. Porém, nos adultos foi observada maior prevalência de casos positivos em pacientes do sexo feminino. Estes resultados estão de acordo com os dados da literatura que registram maior número de casos em crianças e mulheres, provavelmente, devido ao maior contato entre as mães e as crianças infectadas ${ }^{9}$.

№ que concerne à atividade viral, as epidemias por B19 podem ocorrer em intervalos de dois anos, de acordo com estudos realizados em Britain ${ }^{5}$, cujo padrão foi observado em Niterói, RJ ${ }^{14}$. Na região amazônica, a distribuição temporal dos casos foi registrada ao longo de três anos, com atividade viral mais intensa em intervalos que variam de 4 a 5 anos ${ }^{10}$.

Entendemos que esses estudos confirmam a necessidade de elucidar a causa de doencas exantemáticas que ocorrem no Estado do Amazonas e indicam que maiores investigações devem ser feitas em relação à atividade viral.

\section{AGRADECIMENTOS}

A Sra. Maria do Socorre Nobre Tavares pela correção do manuscrito, Lyssia Mara N. Tavares pelo abstracte Marcelo Silva de Oliveira pela confecção dos gráficos e tabelas.

\section{REFERÊNCIAS BIBLIOGRÁFICAS}

1. Anderson LJ. Role of parvovirus B19 in human disease. Pediatric Infectious Diseases Journal 6: 711-718, 1987.

2. Anderson LJ. Human parvoviruses. The Journal of Infectious Diseases 161: 603-608, 1990

3. Anderson MJ, Jones SE, Fisher-Hoch SP, Lewis E, Hall SM, Barlett CR, Cohen BJ, Mortimer PP, Pereira MS. The human parvovirus, the cause of erythema infectiosum (fifth disease) ? Lancet 1:1378, 1983.

4. Caul EO, Usher J, Burton PA. Intrauterine infection with human parvovirus B19: a light and electron microscopy study. Journal of Medical Virology 24: 55-66, 1988.

5. Cohen B. Parvovirus B19: An expanding spectrum of disease. British Medical Journal 311: 1549-1552, 1995.

6. Cossart YE, Field, AM, Cant B, Widdows, D. Parvovirus-like particles in human sera. Lancet 1:72-73, 1975.

7. Cruz AS, Andrade-Serpa MJ, Barth OM, Nascimento, JP. Detection of the human parvovirus B19 in blood donor plasma in Rio de Janeiro. Memórias do Instituto Oswaldo Cruz 84: 279-280, 1989.

8. Cubel RCN, Alferes ACR, Cohen BJ, Nascimento JP. Application to immunoglobulin $\mathrm{M}$ capture hemadherence assays of hemagglutination of monkey erythrocytes by native and recombinant human parvovirus B19 antigens. Journal Clinical Microbiology 33:1997-1999, 1994.

9. Freitas RB, Miranda MF, Shirley J, Tudor R, Desselberger U, Linhares A. Parvovirus B19 antibodies in sera of parients with unexplained exanthemata from Belém, Pará, Brazil. Memórias do Instituto Oswaldo Cruz 48: 497499, 1993.

10. Freitas RB, Wong D, Boswell F, Miranda MFR, Linhares AC, Shirley JA, Desselberg U. Prevalence of human parvovirus B19 and rubellavirus infections in urban and remote rural areas in Northern Brazil. Journal of Medical Virology 32: 203-208, 1990.

11. Kühl U, Pauschinger M, Bock T, Klingel K, Schwimmbeck PL, Seeberg B, Krautwurm L, Poller W, Schultheiss HP, Kandolf R. Parvovirus B19 Infection Acute Myocardial Infarction. Circulation 26: 945-950, 2003.

12. Kuno G, Gomez I, Gubler DJ. Detecting artificial antidengue IgM immune complexes using an enzyme linked immunosorbent assay. The American Journal of Tropical Medicine and Hygiene 36: 153-159, 1987.

13. Miranda MFR, Linhares AC, Shirley JA. Fifth disease in children living in Belém, Brazil. Revista do Instituto de Medicina Tropical de São Paulo 31: 359-362, 1989.

14. Oliveira AS, Brandão AB, Fernandes DG, Bettini LR, Carvalho AB, Pereira ACM, Azevedo KM, Nascimento JP. Human parvovirus B19 infection: clinical and epidemiological study of 24 cases. Revista do Instituto de Medicina Tropical de São Paulo 38:323-327, 1996. 